\title{
Advances in the Design and Application of the Radio- frequency Permeameter
}

\author{
Alvin L. Rasmussen, Albert W. Enfield, and Alfred Hess
}

\begin{abstract}
Improvements are described for increasing the frequency coverage, accuracy, and ease of application of the radiofrequency permeameter developed at the National Bureau of Standards to measure initial complex permeability of toroidally shaped ferromagnetic materials of low conductivity. A brief review of the development of the permeameter is also presented. These improvements include (1) calibration of a permeameter, using a transfer permeability standard, (2) design of permeameter primaries for the frequency range of 0.05 to 50 megacycles, (3) modifications of the short of the permeameter secondary, (4) analysis and modifications of loss equations, (5) graphical methods of obtaining dissipation factor and permeability from measurement data, and (6) capacity calibration of a $Q$ meter.
\end{abstract}

\section{Definition of Symbols}

$\mu_{0}^{\prime}=$ Initial real permeability.

$\mu_{0}^{\prime \prime}=$ Initial magnetic-loss factor.

$L_{a}=$ Geometric inductance of test core.

$\mu_{1}=$ Initial permeability of primary core.

$L_{u 1}=$ Geometric inductance of primary core.

$\mu_{2}=$ Initial permeability of auxiliary core.

$L_{a^{2}}=$ Geometric inductance of auxiliary core.

$L_{2}^{\prime}=$ Geometric inductance of the empty coaxia enclosure of the permeameter.

$R_{0}, L_{0}, X_{0}, Z_{0}=$ Input resistance, inductance, reactance, and impedance, respectively, with permeameter secondary shorted.

$R_{1}, L_{1}, X_{1}, Z_{1}=$ Input resistance, inductance, reactance, and impedance, respectively, with permeameter secondary open.

$R_{f}, L_{f}, X_{f}, Z_{f}=$ Input resistance, inductance, reactance, and impedance, respectively, with permeameter secondary shorted and a sample enclosed.

$C_{0}=$ Capacity required to resonate $L_{0}$.

$C_{1}=$ Capacity required to resonate $L_{1}$.

$C_{f}=$ Capacity required to resonate $L_{f}$.

$Q_{0}, Q_{1}, Q_{f}=Q$ 's corresponding with $C_{0}, C_{1}$, and $C_{f}$, respectively.

$C_{01}, C_{v f}, C_{f 1}=C_{0}-C_{1}, C_{0}-C_{f}$, and $C_{f}-C_{1}$, respectively.

$\omega, f=$ Angular frequency and frequency, respectively.

$N=$ Effective turns ratio of primary to secondary

$X_{2}, Q_{2}=$ Reactance and $\cap$ of secondary without test core, respectively.

$R_{u}, X_{u}, Z_{u}=$ Additional secondary resistance, reactance, and impedance due to sample, respectively.

$M=$ Mutual inductance between primary and secondary.

Tan $\delta_{m}=$ Magnetic-dissipation factor.

$R_{w}, X_{w}=$ Wire resistance and wire reactance of the winding on the permeameter primary, respectively.

$R_{p}=$ Effective series resistance of the primary core.

$X_{p}, Z_{p}=$ Effective series reactance and impedance, respectively, of the primary core.

$Z_{1 f}, Z_{10}=Z_{1}-Z_{f}, Z_{1}-Z_{0}$, respectively.

$X_{1 f}, X_{10}=X_{1}-X_{f}, X_{1}-X_{0}$, respectively.

$L_{1 f}, L_{10}, L_{f 0}=L_{1}-L_{f}, L_{1}-L_{0}, L_{f}-L_{0}$, respectively.

$R_{1 f}, R_{10}=R_{1}-R_{f}, R_{1}-R_{0}$, respectively.

\section{Introduction}

Advances in the design and application of the radiofrequency permeameter are presented.

The permeameter was developed for use in measuring initial permeability $\left(\mu_{0}^{\prime}\right)$ and dissipation factor $\left(\tan \delta_{m}\right)$ of toroidally shaped ferromagnetic materials at radiofrequencies. It is an impedance transformer, the primary of which is wound on a powdered-iron toroid. The secondary is a shorting enclosure that envelops both the primary and the toroidal testsample core, as shown in figure 1. Connections to the primary are brought out to terminals at the bottom of the enclosure. A number of different interchangeable primaries are provided, mounted in plastic cases. One of the shorting ends of the enclosure or section of coaxial line is removable to permit insertion of a toroidal test-sample core. The latter is usually half a centimeter or more above the primary. Thus, a nearly uniform sheet of current surrounds the test sample.

To make measurements, the primary of the permeameter is placed in one arm of an rf impedance bridge or across the terminals of a ? meter. Input impedances of the primary are then measured with: (1) permeameter secondary open, (2) permeameter secondary shorted without sample, and (3) permeameter secondary shorted with a sample enclosed. From these data $\mu_{0}^{\prime}$ and $\tan \delta_{m}$ are derived.

In order to increase the accuracy, precision, ease of application, and frequency coverage of this instrument, the following actions were undertaken, and are discussed in detail.

1. Calibration of a permeameter, using a transfer permeability standard, was introduced.

2. Primaries of the permeameter were designed for the frequency range 0.05 to $50 \mathrm{Mc}$.

3. The quality of the short at the end of the coaxial section was improved.

4. The loss equations were analyzed and proper modifications introduced.

5. Graphical methods of obtaining dissipation factor and permeability from measurement data were developed.

6. Q-meter capacitor increments were accurately calibrated in terms of an external precision capacitor.

The accuracies obtained with the original rf permeameter were not determined exactly [1]. ${ }^{1}$ With the above improvements, the accuracy of permeability obtained from reference to a primary standard

\footnotetext{
1 Figures in brackets indicate the literature references at the end of this paper.
} 


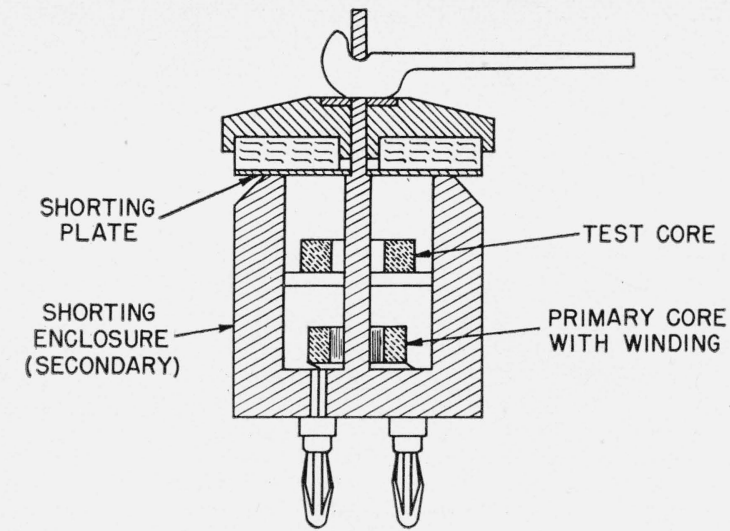

FIGURE 1. Schematic drawing of type $C$ radiofrequency permeameter.

was \pm 2 percent, and the estimated accuracy of the dissipation factor was \pm 10 percent \pm 0.003 . These accuracies applied to the range 0.100 to $35 \mathrm{Mc}$. Low-loss and low-permeability powdered-iron materials, ordinarily difficult to evaluate, have been successfully measured in the improved permeameter.

\section{Discussion}

\subsection{Calibration of a Permeameter, Using a Transfer Permeability Standard}

The equation for initial permeability [1], using the parallel resonance method, is

$$
\mu_{0}^{\prime}-1=\frac{K}{L_{a}} \frac{C_{0 f}}{C_{f 1}^{\prime}}
$$

Permeameter calibration may be defined as an accurate determination of $K$ at a given frequency. This $K$ was formerly determined to an accuracy of 1 percent by means of National Bureau of Standards attenuation and voltage standards and measurement procedures based upon the relationship

$$
K=\frac{1}{\omega^{2} C_{01} N^{2}} .
$$

The effective turns ratio, $N$, of the primary to the secondary was determined from voltage ratios measured with the piston attenuator [2] or the micropotentiometer [3]. Furthermore, $K$ could be determined with reduced accuracy from vacuum-tube voltmeter measurements of the ratio $N$, or from the geometric inductance of the empty space in the permeameter secondary. Above $15 \mathrm{Mc}$ the latter method appeared to be unreliable.

With the newly adopted calibration method, standard permeability cores were used as transfer inductance standards. The real initial permeability, $\mu_{0}^{\prime}$, of a specially ground carbonyl E coaxial sample was determined to an accuracy much better than 1 percent with the primary standard of rf permeability
[4] at the National Bureau of Standards. If the value of $\left(\mu_{0}^{\prime}-1\right) L_{a}$ is such that for the given permeameter $C_{0 f} / C_{f 1}$ approaches unity, then it can be shown that the most accurate determination of $K$ may be made. This condition was met. Also, for best accuracy, high-accuracy bridges were employed. Once a standard sample is available, numerous other secondary standard samples may be obtained from it by means of a permeameter and an accurately capacity-calibrated $Q$ meter. Permeability values determined by means of secondary standard samples at the National Bureau of Standards were within 1 percent of the values obtained from the primary standard of rf permeability. Standard toroidal samples made from powdered-iron materials are best in this application because they usually are quite stable with time, and many have nearly a flatfrequency response of real permeability. The method is relatively simple, more accurate, and more reliable.

\subsection{Design of Permeameter Primaries for the Frequency Range 0.05 to $50 \mathrm{Mc}$}

Re-entrant cavity techniques are used at the National Bureau of Standards down to $50 \mathrm{Mc}$ to measure initial permeability and dissipation factor. The first permeameters were usable at 1 to $5 \mathrm{Mc}$ with either $Q$ meters or rf bridges, whereas at 0.05 to $1 \mathrm{Mc}$, bridges were employed because the inductances of the primaries were too low for application with Q meters. Therefore, high-inductance, high- $Q$ coils were designed to remove this limitation. Additional primaries were designed for the frequency range 0.05 to $50 \mathrm{Mc}$. The following procedure was applied in this design work:

It can be shown [1] that, to a close approximation

$$
K=L_{2}^{\prime}-L_{a 1}=\frac{1}{\omega^{2} N^{2} C_{01}}
$$

and

$$
\mu_{1} L_{a 1}=\frac{1}{\omega^{2} N^{2} C_{1}}
$$

Therefore,

$$
\frac{L_{2}^{\prime}-L_{a 1}}{\mu_{1} L_{a 1}}=\frac{C_{1}}{C_{01}}
$$

Appropriate values of $C_{1}$ and $C_{01}$ were chosen to fall within the range of the instrument applied in the measurement technique. $L_{2}^{\prime}$ was selected after considering the sizes and permeabilities of the materials to be measured in the permeameter; $\mu_{1}$ and $L_{a 1}$ of the primary were determined from eq 5 ; and $L_{a 1}$ was determined from the size of the permeameter. A material with the corresponding $\mu_{1}$, good stability, and relatively high $Q$ for the frequency was selected. A reasonable number of turns (approximately $N$, as determined from eq (4)) was chosen. As the required conditions could not always be met, parameters frequently were adjusted by successive approximations. The secondary inductance was sometimes increased by adding a relatively high permeability 
loading toroid permanently to the secondary. Occasionally, fewer turns than ordinarily used at a frequency were chosen, and a loading toroid was possibly added when measuring very-high-permeability materials. A low-loss external capacitor was sometimes required in this case. The size of the wire on the primary was determined by the frequency of application, by the space available on the primary core, by the number of turns required, and by the best $Q$ 's obtainable.

Parameter restrictions are summarized as follows: When a permeameter-Q-meter combination was employed, $C_{0}$ was usually kept below $400 \mu \mu \mathrm{f}$ at all frequencies to help obtain optimum $Q$ values. For better accuracy, the capacitance difference, $C_{01}$, was made to be $50 \mu \mu$ f or more. $Q$ values were high enough to give proper precision. Based on experience, the minimum values for $Q_{1}$ and $Q_{0}$ were selected as 100 and 25 , respectively; and $N$ decreased with frequency. Typical values of $L_{2}^{\prime}, L_{a 1}, \mu_{1}$, and $N$ are given in tables 1 and 2 of the appendix.

It can be shown that approximately

$$
Q_{0}=\frac{X_{1}-\frac{\omega^{2} M^{2}}{X_{2}}}{R_{1}+\frac{\omega^{2} M^{2}}{X_{2} Q_{2}}} .
$$

As $X_{2}$ and $Q_{2}$ are relatively small at the low frequencies, $Q_{0}$ also becomes very small at these frequencies.

The design of the $0.100-\mathrm{Mc}$ primary (fig. 2) is cited as an example. Six hundred turns of machinewound, extra-heavy-enameled No. 34 wire, banked every 2 or 3 turns to reduce the distributed capacitance and to have the winding extend only $360^{\circ}$ around the toroid, resulted in the most satisfactory $Q$ and a high self-inductance. The toroid ${ }^{2}$ had a $\mu_{1}$ approximately equal to 49. Because, for this case, $C_{0}$ was too large and $Q_{0}$ too small, an auxiliary toroidal core was mounted permanently next to the primary. This core increased $X_{2}$ and resulted in new and usable values of $C_{0}$ and $Q_{0}$.

Therefore, from eq (3)

$$
K=L_{2}^{\prime}-L_{a 1}+\left(\mu_{2}-1\right) L_{a 2} .
$$

Another example (fig. 2) is the $35-\mathrm{Mc}$ primary, which had five turns of a thin pair of copper strips, $1 / 8$ in. wide, wound $360^{\circ}$ around a toroidal core $;^{3} \mu_{1}$ was about 4.8. A thin insulator was applied between turns. To reduce leakage, thin strips were used. Parameters $N$ and $\mu_{1}$ had to be small because of the relatively high frequency involved.

A rather comprehensive list of primary characteristics is given in the appendix, table 2. Each primary covers a limited frequency range about its calibrated frequency, so that measurements are possible practically anywhere over the entire fre-

2 Stackpole Carbon Co., St. Marys, Pa., material type S60.

3 Polydoroff and Associates, Washington, D. C., material carbonyl Super J.

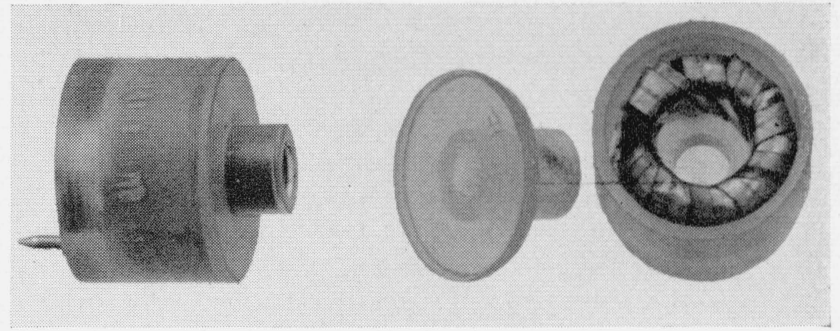

Figure 2. Radiofrequency primaries, 0.100 Mc encased, and 35 Mc disassembled.

quency range of the permeameter. The primaries were especially designed for use with the Boonton $Q$ meter 260A, which has a low- $Q$ scale. The low- $Q$ scale, obviously, is convenient for measuring highloss materials. When rf impedance bridges are used, the frequency range of a primary may be increased many fold because a bridge may have a larger impedance range than a $Q$ meter.

\subsection{Improvements of the Short at the End of the Coaxial Secondary}

This section includes a brief description of all the shorts tested, before discussing the one finally adopted.

Beryllium plate and fingers. The first short, a beryllium-copper plate with a hole in the center, had thick fingers to fit snugly around the center conductor and the inside wall of the outer conductor of the coaxial. A nut pressed this plate against the flat surface of the conductor. The rf resistance of this short was much higher in magnitude than the resistance due to most magnetic materials to be tested, and was nonreproducible, especially for use in the measurement of materials with relatively low permeabilities and dissipation factors.

Thin beryllium fingers ( $0.010 \mathrm{in}$. thick) had similar disadvantages in addition to permanent bending with use. Commercially made folded fingers were no better.

Nonlocking tapers. Two nonlocking $9^{\circ}$ tapers met with some success. Two concentric plates (ref. [1], fig. 1) were used to minimize wear. The larger plate was made of beryllium copper, and the other plate and the rest of the permeameter were made of brass. Furthermore, surface friction between similar metals was reduced. The smooth contact surfaces were lapped circumferentially so that surfaces would fit into each other and make improved electrical contact.

Disadvantages of this shorting method, appearing after the measurement of a few hundred toroids, were contact surface wear and poor reproducibility. Metal from the rubbing contacts would burr and scar the surfaces. However, relapping and cleaning contact surfaces with acetone did slow down this wearing process.

Continuous-surface short. The ideal condition for a reproducible secondary short is for the two faces of the tapers always to meet to form a continuous 
surface from the center conductor to the outer conductor walls inside the permeameter at the same plane. Unusual wear and the stretching of threads cannot be tolerated because they result in electrical contact occurring at numerous places along the threads of the center conductor.

A superior shorting plate was therefore designed. The design principles are applicable to numerous impedance-measuring devices. Figure 1 and figures 3,4 , and 5 show the permeameter assembly details. The stainless-steel clamp exerts downward pressure upon the brass cap, the rubber, and the thin shorting plate, which is made of phosphorus-bronze. The shorting plate is pressed against ledges of the outer conductor and the center conductor. The short is a continuous surface, and the resistance remains as constant as the pressure.

When used with a coaxial line, at $1 \mathrm{Mc}$, the short was reproducible to three ten-thousandths of an $\mathrm{ohm}$, and no variations of inductance were observed with a bridge capable of measuring differences as small as $1 \mathrm{~m} \mu \mathrm{h}$. Contact surfaces were kept clean with acetone and polished occasionally with crocus cloth to maintain such a high degree of reproducibility.

After several thousand measurements, changes of the input impedance of the empty shorted permeameter resulted from the wearing of the surfaces of the center conductor above the clamp. Also, the thin plate showed a very slight impression around the center conductor. These brass surfaces of the center conductor were then replaced with stainless steel. The rubber ${ }^{4}$ in the cap, brass-resistant natural rubber of near Shore hardness 45 , was made suitable for frequent use over a period of at least 2 years.

The rubber and the plate are replaceable, and the permeameter may be easily calibrated with a standard core. The shorting plate pressure must be sufficient to assure good reproducibility. The construction of the center conductor above the shorting plate may be improved by using a stainless-steel section attached to the rest of the center conductor.

Below $0.300 \mathrm{Mc}$ slight variations of pressure appeared to cause more noticeable changes in the input impedance. However, the reproducibility over a long time was still much better than any other shorting arrangement developed thus far at the National Bureau of Standards. Above several hundred kilocycles, the reproducibility of $Q$ 's above 40 may be as good as \pm 1 percent, and of $C^{\prime}$ s, \pm 0.15 $\mu \mu f$. In this design, the narrowed electric-contact surfaces reduced the amount of surface irregularity and assisted in maintaining the good reproducibility.

\subsection{Analysis and Modifications of Loss Equations}

In a former analysis of the permeameter [1] the transformer was implicitly represented by an equivalent network, which included primary core losses with the wire losses, as shown in figure 6,a. They are separated in the network shown in figure $6, b$,

\footnotetext{
${ }^{4}$ Made by F. L. Roth, of Organic and Fibrous Materials Division of the Na-
} tional Bureau of Standards.

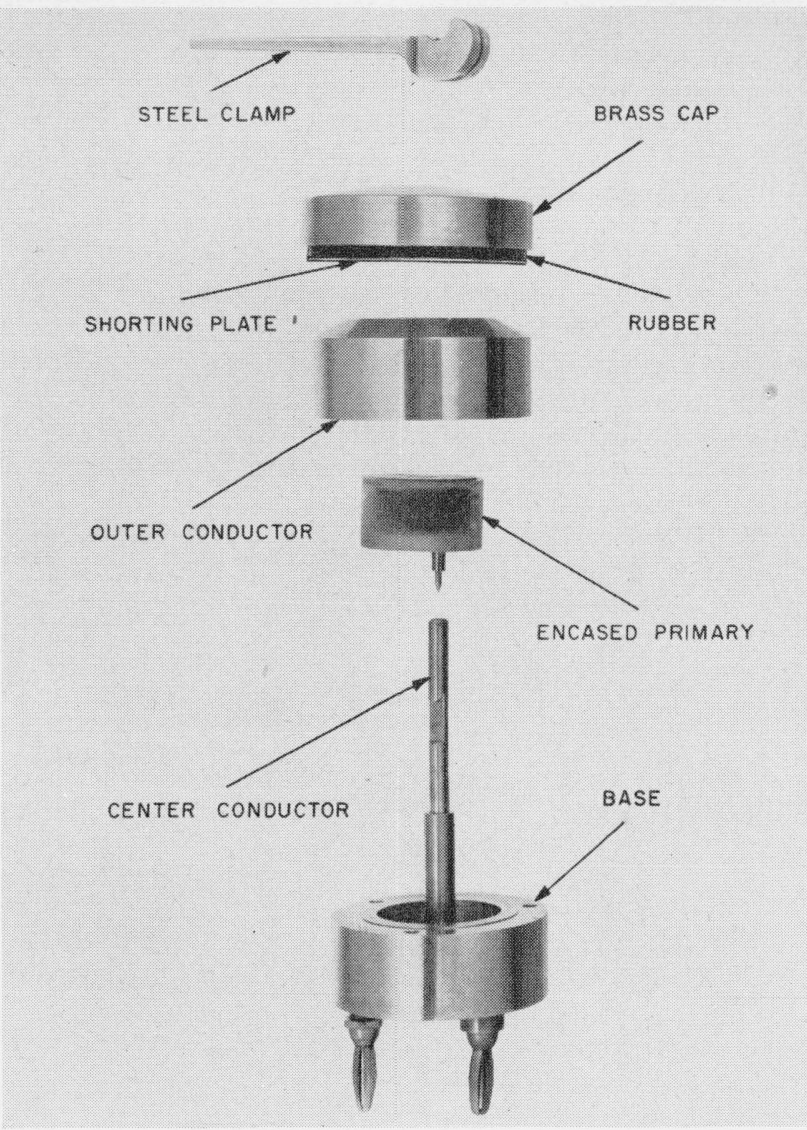

FiguRe 3. Type C radiofrequency permeameter disassembled.

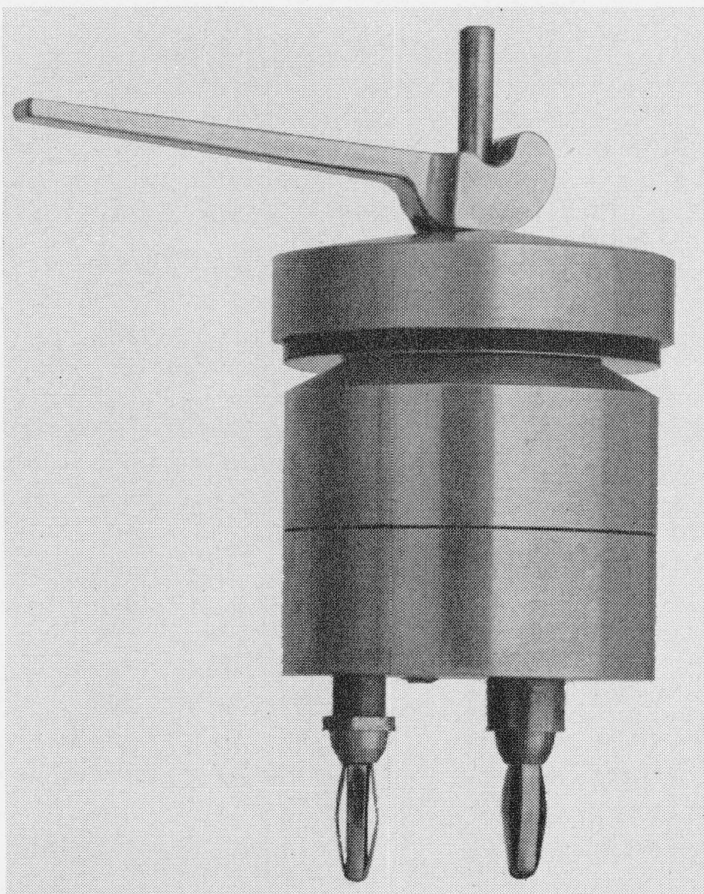

FIGURE 4. Type C radiofrequency permeameter assembled. 


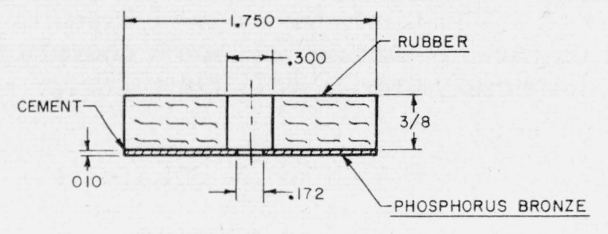

SHORTING PLATE
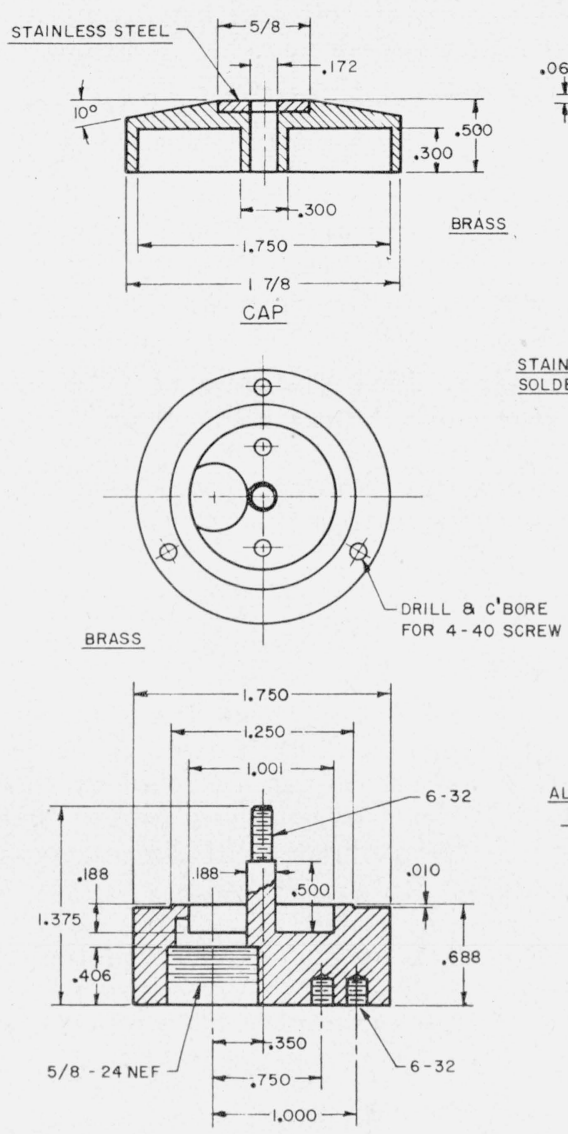

BASE
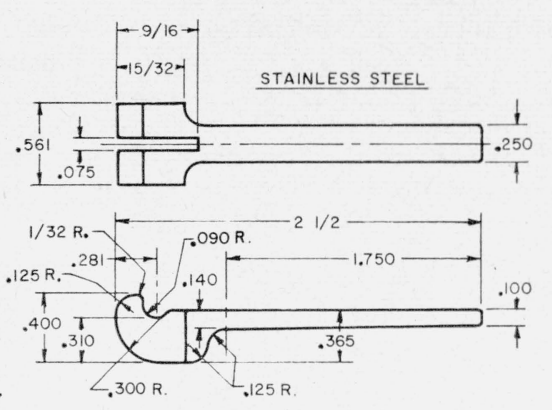

CLAMP

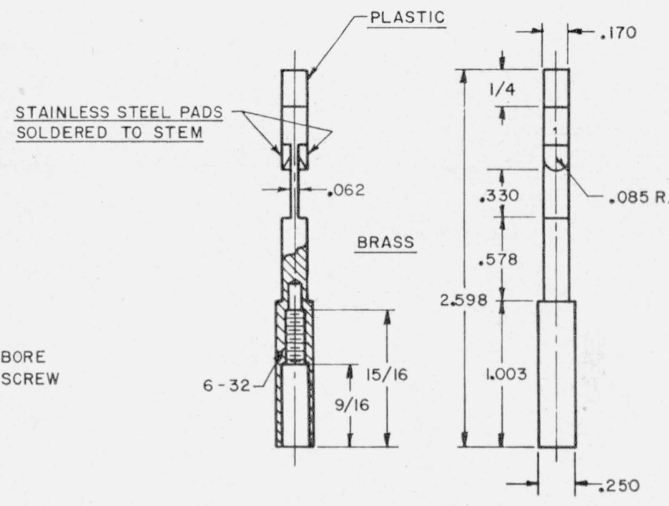

ALL DIMENSIONS

CENTER CONDUCTOR

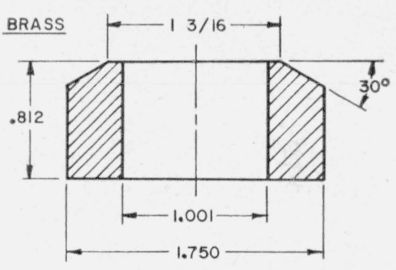

OUTER CONDUCTOR

Figure 5. Details of type C radiofrequency permeameter.
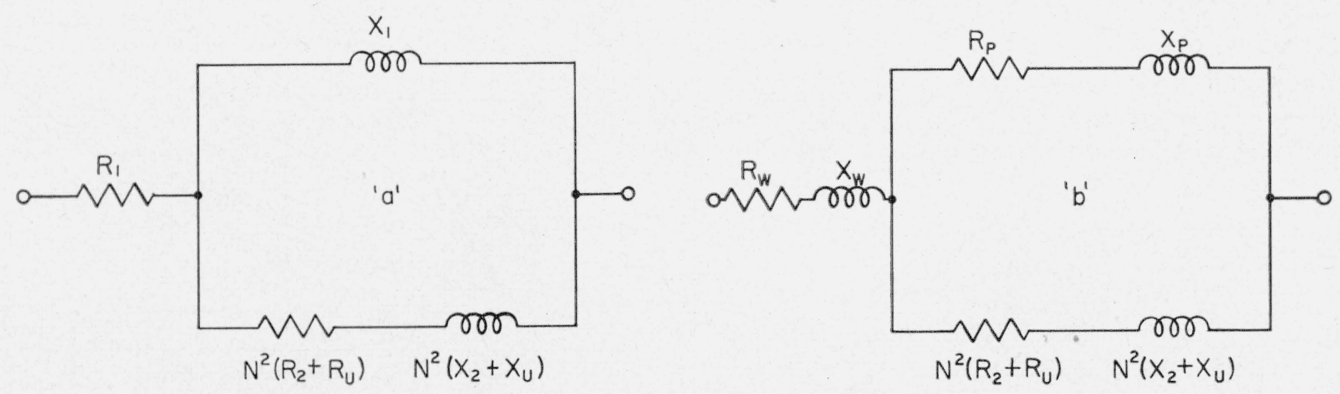

FIGURE 6. Transformer network representations of radiofrequency permeameter. 
in the same manner as used by Kelsall in his original paper [5]. An analysis of the latter network is

$$
\begin{gathered}
Z_{1}=j X_{w}+R_{w}+Z_{p} \\
Z_{0}=j X_{w}+R_{w}+N^{2}\left(\frac{Z_{p} Z_{2}}{Z_{p}+N^{2} Z_{2}}\right) .
\end{gathered}
$$

Subtracting eq (9) from eq (8) and substituting $\left(Z_{2}+Z_{u}\right)$ for $Z_{2}$ and $Z_{f}$ for $Z_{0}$, we have

$$
\frac{Z_{p}^{2}}{Z_{1 f}}-Z_{p}=N^{2}\left(Z_{2}+Z_{u}\right)
$$

Then, eliminating $Z_{2}$, we obtain

$$
Z_{u}=\frac{Z_{p}^{2}}{N^{2}}\left(\frac{1}{Z_{1 f}}-\frac{1}{Z_{10}}\right) .
$$

Experimentally, it is known that $Z_{1 f}$ and $Z_{10}$ are very nearly equal to $X_{1 f}$ and $X_{10}$, respectively.

Thus, simplifying eq (11) gives the equations

$$
N^{2} R_{u}=\left(R_{p}^{2}-X_{p}^{2}\right) A+2 R_{p} X_{p} B
$$

and also

$$
N^{2} X_{u}=2 R_{p} X_{p} A+X_{p}^{2} B,
$$

where $A$ and $B$ are defined as

$$
\begin{aligned}
A & =\frac{R_{1 f}}{X_{1 f}^{2}}-\frac{R_{10}}{X_{10}^{2}} \\
B & =\frac{1}{X_{1 f}}-\frac{1}{X_{10}} .
\end{aligned}
$$

Now, dissipation factor is defined as

$$
\frac{\mu_{0}^{\prime \prime}}{\mu_{0}^{\prime}}=\frac{R_{u}}{\omega \mu_{0}^{\prime} L_{a}}=\frac{R_{u}}{X_{u}}\left(\frac{\mu_{0}^{\prime}-1}{\mu_{0}^{\prime}}\right) .
$$

Therefore,

$$
\tan \delta_{m}^{\prime}=\left[\frac{\left(\frac{R_{p}^{2}}{X_{p}^{2}}-1\right) \frac{A}{B}+2 \frac{R_{p}}{X_{p}}}{1+2 \frac{R_{p}}{X_{p}} \frac{A}{B}}\right]\left(\frac{\mu_{0}^{\prime}-1}{\mu_{0}^{\prime}}\right),
$$

where the prime is used to designate a closer approximation than given in reference [1].

The expression $A / B$ may be written as

$$
\frac{A}{B}=\frac{L_{10} L_{1 f}}{\omega L_{f 0}}\left(\frac{R_{1 f}}{L_{1 f}^{2}}-\frac{R_{10}}{L_{10}^{2}}\right) .
$$

This expression is exactly the negative of the expression for $\tan \delta_{m}[1]$, which is

$$
\tan \delta_{m}=\frac{L_{10} L_{1 f}}{\omega L_{f 0}}\left(\frac{R_{f 1}}{L_{1 f}^{2}}-\frac{R_{01}}{L_{10}^{2}}\right) .
$$

Furthermore, $R_{p} / X_{p}$ is of the order of magnitude of the dissipation factor of the primary core. For low-loss material, $\tan \delta_{m} \ll 1$, therefore,

$$
2 \frac{R_{p}}{X_{p}} \tan \delta_{m} \ll 1 \text {. }
$$

Consequently, the dissipation factor $\left(\tan \delta_{m}^{\prime}\right)$ may be expressed in terms of tan $\delta_{m}$ and of the dissipation factor of the primary core as follows:

$$
\tan \delta_{m}^{\prime}=\left(\tan \delta_{m}+2 \frac{R_{p}}{X_{p}}\right)\left(\frac{\mu_{0}^{\prime}-1}{\mu_{0}^{\prime}}\right) .
$$

When materials with a dissipation factor of the same order of magnitude as the primary core are measured, eq (21) should obviously be used.

\subsection{Graphical Methods of Obtaining Dissipation Factor and Permeability from Measurement Data}

When the permeameter is used with a $Q$ meter, it can be shown that ${ }^{5}$

$\tan \delta_{m}=\frac{C_{01} C_{f 1}}{C_{0 f}}\left[\frac{1}{C_{f 1}^{2}}\left(\frac{C_{f}}{Q_{f}}-\frac{C_{1}}{Q_{1}}\right)-\frac{1}{C_{01}^{2}}\left(\frac{C_{0}}{Q_{0}}-\frac{C_{1}}{Q_{1}}\right)\right]-\frac{2}{Q_{1}}$

Computing $\tan \delta_{m}$ from this equation is obviously a lengthy process. It would be more convenient to obtain values of tan $\delta_{m}$ from graphs. The graphs could be used over a long period because, as stated before, the application of the improved permeameter results in measurements with a high degree of reproducibility.

One may, by using permeameter data obtained in conjunction with a $Q$ meter at some given frequency, plot $C_{f} / Q_{f}$ versus $C_{f}$ by using a family of $\tan \delta_{m}$ curves [6]. Tan $\delta_{m}$ values (fig. 7) are easily derived through

5 Equation (22) is a simplification of dissipation factor eq (26) in ref. [1].

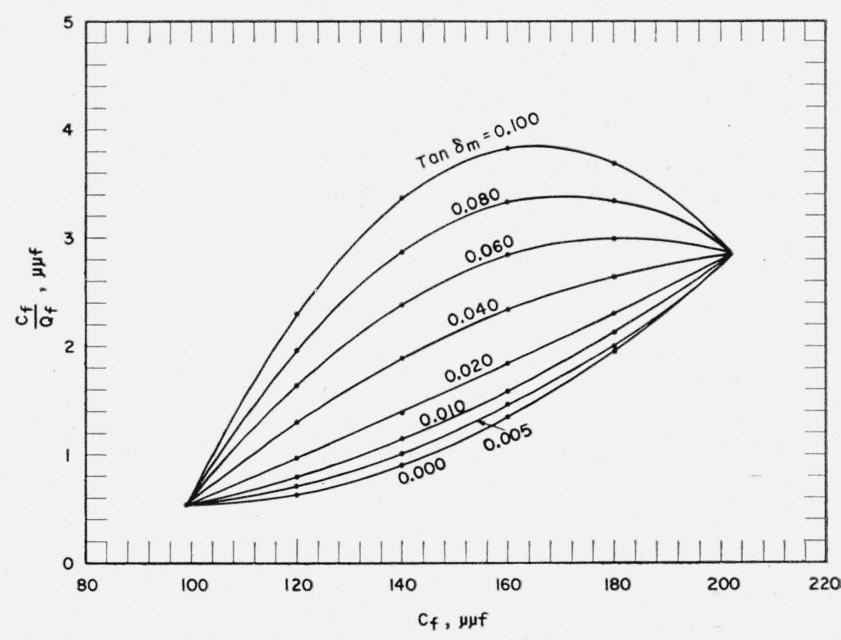

Figure 7. $C_{f} / Q_{f}$ versus $C_{f}$, using a family of tan $\delta_{m}$ curves for permeameter and $Q$ meter at one frequency. 


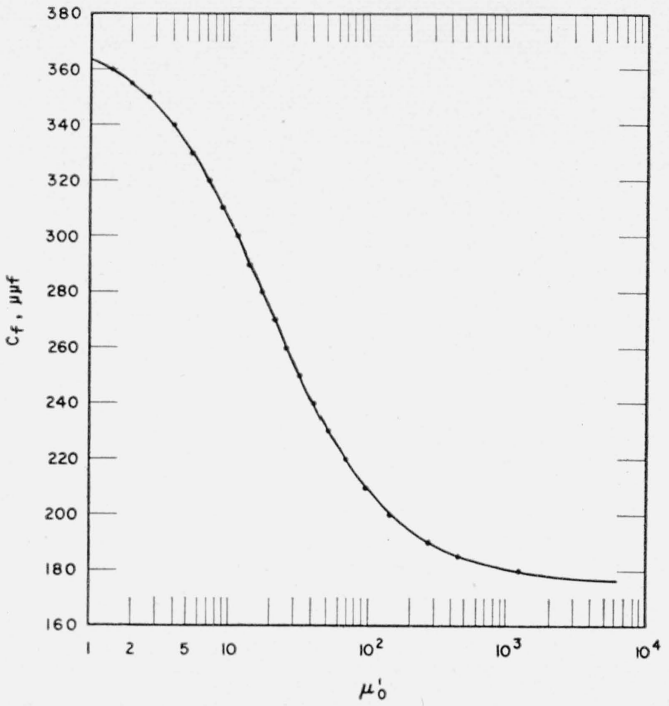

FIGURE 8. $C_{f}$ versus $\mu_{0}^{\prime}$ for permeameter $K / L_{a}=20$ and $Q$ meter at one frequency.

interpolation between tan $\delta_{m}$ curves after locating coordinates on a graph. Several graphs at other frequencies may be constructed to cover effectively the desired frequency range.

If a large number of cores, having approximately the same value of $L_{a}$, are to be measured at one frequency on a calibrated $Q$ meter, considerable time may be saved by again using a graph (fig. 8). $C_{f}$ versus $\mu_{0}^{\prime}$ is plotted on semilogarithmic paper, with $C_{f}$ as the linear coordinate. The end points on the graph are determined from the values of $C_{1}$ and $C_{0}$, and $C_{f}$ is plotted in $10-\mu \mu$ f steps over the center part of the range and in 5- $\mu \mu \mathrm{f}$ steps near the ends. The point of inflection of the curve occurs when the ratio $C_{0 f} / C_{f 1}$ equals unity. The shape of the curve will vary according to $\bar{L}_{a}$ value used.

\subsection{Capacity Calibration of a $Q$ Meter}

The capacitance of a $Q$ meter, while corresponding to the dial reading to good accuracy, is not a smooth function of the dial reading; hence capacitance differences as read can be in error by a large amount and may even be opposite in the direction of change.

To reduce this error, the Q-meter capacitor was calibrated against a more precise capacitor by using a direct substitution method. To facilitate this cali- bration and subsequent measurements, an enlarging lens with a vertical hairline was mounted in front of the dial to eliminate parallax and enable more precise reading.

It was found that sufficient accuracy could be obtained by using a $2.5-\mathrm{mh}$ coil at $130 \mathrm{kc}$ and a $100-$ to $1100-\mu \mu \mathrm{f}$ precision rf capacitor connected with short leads. This combination gave high $Q$ for precise reading, and the frequency was low enough that corrections were not necessary for lead inductance.

The radiofrequency permeameter described in this paper has been modified for measuring complex permeability as a function of temperature and directcurrent bias. Other modifications have been considered.

\section{References}

[1] P. H. Haas, A radiofrequency permeameter, J. Research NBS 51, 221 (1953) RP2454.

[2] R. E. Grantham and J. J. Freeman, A standard of attenuation for microwave measurements, Trans. Am. Inst. Elec. Engrs. 67, 535 (1948)

[3] M. C. Selby, Accurate radio-frequency microvoltages, Communication and Electronics, No. 6, 158 (May 1953)

[4] High frequency calibration of magnetic materials, NBS Tech. News Bul. 36, 158 (Oct, 1952).

[5] G. A. Kelsall, Permeameter for alternating current measurements at small magnetizing forces, J. Opt. Soc. Am. and Rev. Sci. Instr. 8, 334 (Feb. 1924).

[6] G. P. McKnight, Permeameter for radio frequencies, Elec. Mfg. 52, No. 4, 150 (Oct. 1953).

\section{Appendix. Permeameter Dimensions and Description of Primaries}

TABLE 1. Dimensions of five permeameters

\begin{tabular}{|c|c|c|c|c|c|}
\hline & \multicolumn{5}{|c|}{ Type of permeameter } \\
\hline & \multicolumn{2}{|c|}{$A$ (tapered shunt) } & \multicolumn{2}{|c|}{$B$ (tapered shunt) } & \multirow{2}{*}{$\begin{array}{c}C^{\mathrm{a}} \\
\text { (Pressure } \\
\text { shunt) }\end{array}$} \\
\hline & $a^{\text {a }}$ & $b$ & $a$ & $b$ & \\
\hline Height $(H)$, in ....... & 1. 032 & 1. 188 & 1. 188 & 1. 288 & 1.000 \\
\hline $\begin{array}{l}\text { Inside diameter }(2 A) \text {, } \\
\text { in }\end{array}$ & 0.188 & 0.188 & 0.250 & 0.250 & 0.250 \\
\hline $\begin{array}{l}\text { Outside diameter } \\
(2 B) \text {, in }\end{array}$ & 1. 000 & 1.000 & 1. 600 & 1. 600 & 1. 001 \\
\hline $\begin{array}{l}\text { Geometric induct- } \\
\text { ance of the empty } \\
\text { secondary }\left(L_{2}^{\prime}\right)^{\mathrm{b}}, \mathrm{h} \text {. }\end{array}$ & 8. $76 \times 10^{-9}$ & $10.1 \times 10^{-0}$ & 11. $2 \times 10^{-0}$ & $12.1 \times 10^{-9}$ & $7.05 \times 10^{-0}$ \\
\hline
\end{tabular}

a Designed especially for measuring powdered-iron materials.

b $L_{2}^{1}=2 H(\ln B / A) \times 10^{-7} \mathrm{~h}$, where $H$ is in meters. 
TABLE 2. Examples of wound primaries in various permeameters

\begin{tabular}{|c|c|c|c|c|c|c|c|c|c|c|}
\hline \multirow{2}{*}{$\begin{array}{l}\text { Calibra- } \\
\text { tion fre- } \\
\text { quency, } f\end{array}$} & \multirow{2}{*}{ Core material a } & \multirow{2}{*}{$\begin{array}{l}\text { Approxi- } \\
\text { mate } \\
\text { value of } \\
\text { perme- } \\
\text { ability, } \\
\mu_{1}\end{array}$} & \multirow{2}{*}{$\begin{array}{l}\text { Number of turns b } \\
\text { and kind of wire }\end{array}$} & \multirow{2}{*}{$\begin{array}{c}\text { Permeameter } \\
\text { applied }{ }^{\circ}\end{array}$} & \multirow{2}{*}{ Remarks } & \multirow{2}{*}{$\begin{array}{c}\text { Permeameter } \\
\text { with char- } \\
\text { acteristics } \\
\text { given in } \\
\text { columns } \\
\text { at right }\end{array}$} & \multicolumn{4}{|c|}{$\begin{array}{l}\text { Approximate values } \\
\text { of capacitance and } \\
Q\end{array}$} \\
\hline & & & & & & & $C_{1}$ & $Q_{1}$ & $C_{0}$ & $Q_{0}$ \\
\hline $\begin{array}{l}M c \\
0.100\end{array}$ & $\begin{array}{l}\text { Stackpole S60, with } \\
\text { auxiliary S60 core.d }\end{array}$ & 49 & 600 ; No. 34 Formex .... & All five...... & $\begin{array}{l}\text { Machine wound, with frequent } \\
\text { banking of turns. }\end{array}$ & $C$ & $\begin{array}{l}\mu \mu f \\
169\end{array}$ & 169 & $\begin{array}{l}\mu \mu f \\
377\end{array}$ & 41 \\
\hline .300 & $\begin{array}{l}\text { Stackpole S60, with } \\
\text { auxiliary S60 core. }\end{array}$ & 49 & 250 ; No. 34 Formex & $C_{--}$ & $\begin{array}{l}\text { Machine wound, with about } \\
0.1 \text {-in. spacing between every } \\
\text { group of } 40 \text { or } 50 \text { turns around } \\
\text { the core. }\end{array}$ & $C$ & 118 & 143 & 329 & 44 \\
\hline .675 & Carbonyl E. & 8.9 & $\begin{array}{l}\text { 180; } 10 \text {-strand Litz No. } \\
38 \text {. }\end{array}$ & $A a$ and $A b_{-}$ & & $A a$ & 209 & 146 & 431 & 30 \\
\hline 1 & _..... do & 8. 9 & 164; No. 34 Formex & All five.. & & $C$ & 140 & 167 & 289 & 36 \\
\hline 1 & -..... do & 8.9 & $\begin{array}{l}\text { 140; } 10 \text {-strand Litz No. } \\
41 \text {. }\end{array}$ & .....do ... & Occasional banking of turns... & $C$ & 189 & 242 & 388 & 40 \\
\hline 1. 5 & -.... do & 8.9 & $\begin{array}{l}\text { 100; } 10 \text {-strand Litz No. } \\
41 \text {. }\end{array}$ & ..... do. & & $C$ & 177 & 200 & 364 & 41 \\
\hline 2.5 & Carbonyl SF & 7.8 & 62; No. 24 Formex & _..._do_ & & $A a$ & 157 & 194 & 286 & 53 \\
\hline 3 & Carbonyl E- & 8. 9 & 50 ; No. 24 Formex & ..... do.. & -..... & $C$ & 164 & 195 & 351 & 53 \\
\hline 3 & Carbonyl SF . & 7.8 & 50 ; No. 24 Formex & ..... do. & & $C$ & 186 & 232 & 359 & 76 \\
\hline $\begin{array}{r}5 \\
10\end{array}$ & _.... do do & $\begin{array}{l}7.8 \\
7.8\end{array}$ & $36 ;$ No. 24 Formex & ...... do do & & $\stackrel{C}{C}$ & $\begin{array}{r}99 \\
157\end{array}$ & $\begin{array}{l}183 \\
167\end{array}$ & $\begin{array}{l}202 \\
317\end{array}$ & $\begin{array}{l}70 \\
80\end{array}$ \\
\hline 15 & do & 7.8 & $15 ;$ No. 20 Formex & do & & $C$ & 67 & 139 & 139 & 90 \\
\hline 30 & Polydoroff Super J & 4.8 & $\begin{array}{l}5 \text {; thin pairs of copper } \\
\text { strips, } 1 / 8 \text { in. wide. }\end{array}$ & $C_{-}$ & $\begin{array}{l}\text { Dimensions affect values at right } \\
\text { more than at lower frequen- }\end{array}$ & $C$ & 179 & 123 & 252 & 93 \\
\hline 35 & .... do & 4. 8 & $\begin{array}{l}5 \text {; thin pairs of copper } \\
\text { strips, 1/8 in. wide. }\end{array}$ & $C_{-}$ & do & $C$ & 130 & 126 & 184 & 99 \\
\hline
\end{tabular}

a The size of all primary cores was approximately: $2 A=0.505 \mathrm{in} ., 2 B=0.795 \mathrm{in}$., and $H=0.325 \mathrm{in}$., where $L_{a 1}=0.75 \times 10^{-9} \mathrm{~h}$. b Number of turns is approximately equal to the turns ratio $N$.

- See table 1 for specifications.

d At 0.100 Me the sizes of the auxiliary core were approximately:

Permeameters $A$ and $C$

$2 A=0.255$ in, $2 B=0.345$ in., and $H=0.430$ in.

Permeameters $A$

At 0.300 Mc with permeameter $C$, the size of the auxiliary core was approximately:

$2 A=0.255$ in., $2 B=0.345$ in., and $H=0.220 \mathrm{in}$

Boulder, August 19, 1955. 